\title{
Exploring School-Based Mentors' Assessment of Practicum in Diverse Teaching Contexts
}

\author{
Thomas D.T. Sedumedi \\ Fhatuwani J. Mundalamo \\ Department of Mathematics, Science and Technology Education, Tshwane University of Technology. South Africa \\ Emails: sedumeditdt@tut.ac.za, mundalamofj@tut.ac.za
}

\section{Doi:10.5901/mjss.2014.v5n27p821}

\section{Abstract}

Practicum is one of the important processes preservice teachers engage in during their preparation. In this study, we explored school-based mentors' (SBMs) assessment and feedback comments of preservice teachers' (PSTs) teaching ability during practicum. We aimed specifically to assess mentors' judgment comments on lesson teaching activities during a six-week practicum in diverse teaching contexts. For a deeper understanding of the judgment comments, we invoked two theories; the cultural historical activity theory (CHAT) and the social judgment theory (SJT). We collected and analysed data through qualitative and quantitative methods. Our findings show that mentors' judgment comments vary across and within contexts. That is, assessment comments differed between individual mentors within and across contexts in terms of what assessors focused on or about the aspects of the criteria that were mentioned in their comments. As for the quality (e.g. comprehensiveness, accuracy or appropriateness) of the judgment comments (as feedback), mentors were not comprehensive in their comments and their reference to criteria was limited and in some cases inconsistent. In some instances, comments were inappropriate; they did not add any formative value or relate to the criteria. Generally, mentors' feedback comments lacked usefulness to the university educator's and preservice teacher's formative purposes. In conclusion, the study highlights the importance of quality and equity of and in assessment, especially of the same cohort in diverse teaching contexts. That is, there is the need for an assessment instrument that would ensure that most aspects of the criteria are comprehensively assessed and commented on, especially for formative purposes.

Keywords: Practicum; mentoring; assessment judgment; activity; quality

\section{Introduction}

This study explores assessment judgment comments school-based mentors (SBMs) make about preservice teachers' teaching capabilities during practicum in different social, environmental and classroom contexts. We argue that the differences in these assessment judgments are a product of many and varied contextual factors. That is, contexts in which SBMs assess PSTs' teaching capabilities influence their decision-making processes and their final judgment comments to some extent. The SBMs' decision-making processes are obviously influenced by different teaching and learning environments or their social contexts. Included in the factors affecting assessment judgments and/or the comments SBMs make during practicum are their conceptions of teaching and learning and the dialogues they hold with their PSTs during mentoring. Therefore, the relationships that mentor and mentee build within mentoring sessions largely determine or influence the outcome of mentoring processes, including the mentor's assessment judgments about PSTs' teaching competences.

Given the complex nature of what happens in mentoring, it would be appropriate to clarify what constitutes mentoring and/or the roles mentors play or should play in mentoring sessions. We use Hudson, Spooner-Lane and Murray's (2012) description of the roles of the SBM (mentor) and PST (mentee) in the mentoring dyad, namely that mentoring "involves a productive and professional relationship". In this relationship "the mentor uses personal attributes to model and articulate the education system requirements and pedagogical knowledge for guiding the mentee's development" (p.2). This description touches on aspects of the assessment judgment comments we aim to assess. It clarifies 'what' the mentor is supposed to do, and 'how' and 'why' s/he has to do it in the mentoring process. Knowing the elements of the comments we aim to assess provides us with a 'window' through which we can understand the nature and basis of mentors' assessment judgment comments about their PSTs' teaching practice or capabilities. This understanding ensures access into the mentor's judgment about or of the different types or forms of knowledge 
demonstrated in PSTs' teaching abilities (Smith, 2010), individually or in an integrated form.

Assessing SBMs' judgments constitutes an assessment of their feedback to both themselves (as mentors) and their mentees (PSTs). It is a reflection of their own abilities to guide and develop PSTs in a mentorship relationship. For our purpose, assessing mentors' assessment allows us to 'see' through the mentor's 'mirror' of assessment judgments the extent to which the mentor is able to negotiate his/her way through the conflicting roles of the difficult mentorship position. Mentors' recognition of their own abilities, the PSTs' prior knowledge and learning styles, as well as of the learning environments and social contexts is important for their informed and honest judgment of teaching abilities (Crasborn, Hennissen, Brouwer, Korthagen \& Bergen, 2008). Conversely, our accurate assessment of the mentors' assessment judgments through their comments depends on our judgment of the diverse environments and social contexts that mentors are immersed in when engaging with PSTs in their complex and multiple positions as mentors and assessors. In this study therefore, and as a way to understand the differences in assessment judgment outcomes among mentors, we assessed the nature, content and quality of school-based mentors' assessment judgments. These assessment judgments/comments are in effect the feedback about what they consider important practice teaching lessons during practicum. The questions we aim to answer in this study are as follows:

- What is the nature and content of mentors' assessment judgment comments on PSTs' teaching capabilities? Assessment of the nature and content in this study was limited to written comments as reflected in the teaching practice journal. The nature and content of the comments provide a measure of how SBMs reflect on PSTs teaching activities.

- What features did SBMs mostly focus on in their assessment judgment comments of PSTs teaching actions and/or abilities?

With this question, our aim was to establish the extent of the different areas SBMs focus on in their comments about PSTs teaching practice abilities in relation to the criteria as set out in the teaching practice journal.

- What is the quality of SBMs' assessment judgment comments of the lesson teaching capabilities of PSTs?

The intention with this question was to reflect on the SBMs assessment judgment comments against the criteria as set out in the assessment instrument. These comments are in effect the SBMs' feedback to PSTs and their university educators about their teaching capability. In other words, the comments need to serve a formative purpose. According to Sadler (1998), quality or effective feedback must be accurate, comprehensive, appropriate, and accessible.

\section{Assessment as a Critical Factor in Practicum Mentoring Processes}

Mentoring is considered a critical aspect of the practicum activity (Leshem, 2012; McDougall, Mtika, Reid \& Weir, 2013). However, there is a plethora of mentoring definitions and/or related practices that make this concept slippery. These varied mentoring practices are further made complex by different assessment approaches. The differences become more pronounced and diverse in different learning and social contexts; hence, assessment outcomes may differ between mentors and with changing teaching and learning environments or social contexts. With differing mentors' assessment judgment comments, the validity and reliability of assessment during practicum becomes a challenge of quality and equity in teacher preparation. Hogdson (1976) highlights Morris' (1970) concerns about the difficulties inherent in the assessment of teaching abilities, especially where grading is the dominant assessment approach. Two major points of his argument are that: (1) grading marks allocated for practice teaching lack validity as they reflect a limited number of teaching skills, and (2) grading as an assessment approach is not reliable and cannot be reproducible.

Despite Morris' (1970) almost forty-three years of concerns about the limitations of grading, assessment by grading is still predominantly used in teaching practicum assessments. Another dimension of this argument is Sadler's (1998), namely that "grades and marks do not deliver as much formative effectiveness as tailored comments" and can be counterproductive with students of lower ability (p.77). Although grading as an assessment approach for teaching ability has long raised serious concerns, this does not mean the approach should be discarded. In fact, there is a counter argument to discarding it. The suggestion is that it should be complemented with other methods to enhance the comprehensibility of assessment for higher levels of reliability of the assessment process and outcomes (Dall'Alba \& Sandberg, 2006; Darling-Hammond \& Bransford, 2005). We support assessment that will aid guidance of PSTs as future teachers. Multiple methods of assessment are ideal, especially in different learning environments or social contexts; "no single source in the appraisal of performance has ultimate legitimacy or warranty" (Tillema, 2009, p.156). Assessment in all its forms or manifestations linked with development should be viewed as 'pillars' on which mentoring must be anchored.

Although we support and encourage multiple assessment approaches, our focus is on formative purposes of 
assessment as important elements of mentoring. Tillema (2009) argues that formative assessment "tries to document and illuminate the cyclical and extended process of professional growth and the building of relevant practice experiences" (p.156). In other words, formative assessment of teaching practicum informs both the mentor and the PST about what action to take to enhance both teaching and learning to teach. Formative assessment continuously links assessment to development (Black \& William, 1998). Taras (2002) emphasizes our point that "examining assessment practice is...a useful means of gauging change and development in higher education since it impacts directly or indirectly on other processes" (p.503). Black and William (1998) contend that formative assessment is effective in all educational settings and hence its examination may be ideal, as it would affect other processes in different environments and social contexts.

\subsection{Assessing assessment judgment comments in context}

The major challenge of mentoring lies in its idiosyncratic nature. This aspect of mentoring is bound to affect some of its processes (e.g. assessment) and the outcomes thereof. As indicated earlier, our aim was to assess the nature and content of assessment judgment comments and the quality of outcomes they reflect about PSTs' teaching abilities during a school-based practicum. Assessment judgment comments in this study comprise the SBMs' written "representation of an assessed person's knowledge, skill or understanding" of teaching of a lesson (Newton, 2007, p.158). In addition, this study attempts to reflect on the mentoring and assessment system used by mentors in assessing the PSTs' lessons. In light of this complex process, an all encompassing and effective framework was imperative. That is, the theoretical framework used in the study must enhance our ability to understand the SBMs' assessment outcomes or their judgment comments of PSTs' teaching abilities in diverse learning environments and/or different social contexts. Diversity in contexts - geographical, environmental, historical, cultural, economical, academic and experiential, especially for mentor teachers (SBMs) - adds to the already near impossible situation for the study.

We discuss some of the elements of the idiosyncratic nature of mentoring contributing to this complexity below.

- Mentors and PSTs bring different beliefs and concerns into the mentoring process, which results in complex interactions and complicated dynamics during mentoring dialogue sessions (Hawkey, 1997). These differences (e.g. beliefs) may compromise assessment processes, leading to biased assessment judgment comments from the mentor and in the process unsettling the PST. This unsettled environment may consequently lead to tensions that would produce unreliable assessment environments and outcomes of the PSTs' practice teaching ability. In addition, perceptions about mentoring processes can affect the relationships and the learning process that develops for both mentor and the PST by influencing how they communicate and what advice is given (Wang, 2001).

- SBMs bring into preservice teacher preparation or mentoring situations diverse practical knowledge backgrounds gathered over years of teaching and learning experiences. Teachers' backgrounds and experiences affect their judgments during their activities both as mentors and assessors. According to Beijaard and Verloop (1996), practical knowledge is the "teachers' knowledge of classroom situations and the practical dilemmas they face in carrying out purposeful action in these settings" (p.277). This knowledge differs from teacher to teacher and will influence their assessment judgments or comments on situations differently. In their positions as mentors of PSTs they will have different views on how PSTs perform during practicum in different or the same contexts.

- Different learning and teaching environments for the PST and mentor respectively may influence their conceptualisation of teaching and, subsequently, their views of the processes of learning to teach and their vision of the role of the mentor (Maynard \& Furlong, 1993). These differences are a challenge to their mentoring dialogue sessions and may have implications for a successful mentoring relationship and the learning-to-teach abilities of the PSTs.

In this mentoring situation, it would be difficult to have consistent assessment outcomes, because judgments are intrinsically linked with the backgrounds of both the PSTs and their mentors. Backgrounds here may refer to the knowledge (which in this case is different), their individual cultures, the educational institutions' cultures (university and school), historical backgrounds of local education structures, etc. These differences bring into the mix different educational environments and social contexts. The challenge to SBMs is how to engage PSTs in this contextual milieu. Against this background, our aim is to better understand the nature and content and the quality of the assessment comments they make about PSTs' practice teaching abilities. These, we argue, are context dependent.

Clearly, this complexity requires a holistic framework to assist us in selecting relevant theoretical and practical tools to enable access to the contents of their judgment comments and/or their rationale for arriving at such assessment judgments. In this regard, we invoked the cultural historical activity theory (CHAT). According to Roth and Lee (2007), the 
CHAT and "its inherently dialectical unit of analysis allows for an embodied mind, itself as an aspect of the material world, stretching across social and material environments" (p.189). We believe that the CHAT will enhance our understanding of SBMs' assessment judgments as they (Crossouard, 2009), "are mediated and shaped by the material and symbolic tools available in the socio-cultural settings" of their activities (p.79). That is, as researchers we should not only focus our interpretations of SBMs' judgments purely on their comments but also reflect on the socio-cultural milieu in which these judgments are made.

According to Engeström (1987), the SBMs and the PSTs operate in diverse social context systems. These systems include and are evolving over historical cycles. In the case of our study, the evolving cycles include the changing education systems and cultures of both the communities of practice and political environments. CHAT will allow for interpretations within the different contexts and/or environments in which mentoring of PSTs takes place and may necessarily yield different assessment judgments which, in turn, would eventually produce or reflect different identities among the assessed (Crossouard, 2009). In its wake, CHAT (Roth \& Lee, 2007) "theorizes persons continually shaping and being shaped by their social contexts that immediately problematise knowledge as something discrete or acquired by individuals" (p.189).

It is also important that assessment comments are always reliable and valid. For this purpose, we complement the CHAT with the social judgment theory (SJT). That is, we must be clear about what is assessed, how it should be assessed and why it is assessed, especially in different and complex social settings. Haigh, Ell and Mackisack (2013) describe the SJT as "attempts to model how judgments are made in complex social settings". With the SJT we are able to adapt our approaches and therefore "understand and improve important judgment processes" (p.2) to ensure accuracy, comprehensiveness and appropriateness of our assessment of mentors' assessment judgments, especially on instructional and psychological support of PSTs. Gold (1996) argues for two types of support. Instructional support enhances knowledge and skills development. Psychological support on the other hand builds confidence and encourages self-esteem. However, the instrument for assessment does not accommodate these aspects. In our assessment of the mentors' feedback (assessment judgments), we need to establish if mentors in their assessments did focus on these supports, since the role of the mentor is to induct and support the PST. The SJT is therefore useful as we attempt to refine and reinforce our assessment of both the system used by the assessor (SBM) and his/her own assessment or reflection on his/her activities.

As the role of the SBM is to induct and support the PST into the profession of teaching, we argue that it is only through a refined and accurate assessment of the PST that s/he may know what, how, why and when to assess. In this study, these questions focus on the variables (criteria) of understanding the PST's practice teaching of a lesson. These variables include aspects of: mastery of learning content; the PST's didactic flexibility; ability to communicate with the learners; actualisation of content; the use of teaching media and/or materials; and the application of teaching methods. These variables are part of the instrument used for assessing the teaching of a lesson.

\section{The Study}

\subsection{Context of Study}

The study is an exploration of SBMs' assessment of PSTs' practice teaching lessons during a six-week practicum in schools. During this period, each PST is assigned a mentor teacher for a specific teaching subject. The study was conducted among University of Technology (UoT) students in South Africa. The university caters for students from diverse teaching and learning environments and/or social contexts. The student population is therefore made up of ethnic, cultural, geographical and socio-economically diverse groupings. The focus of the study is on second-year Bachelor of Education (BEd) programme preservice teachers $(n=53)$. That is, the population of this study comprises 53 individual preservice teachers' teaching practice journals (TPJs). Of these TPJs, four groups were formed according to the origins (i.e. province or environment) of preservice teachers. That is, a group is made up of TPJs from a particular context.

\subsection{Design of Study}

This study used a mixed-methods approach. The qualitative aspect of the study was a multiple case study of four cases from different contexts. In each case, the TPJs were purposively to reflect a particular context. Each case consisted of three TPJs from which SBMs' comments were drawn. It is within these cases that the nature and content and the quality of mentor's assessment judgment comments about PSTs' teaching abilities were explored to establish what was 
assessed and the particularity of the features or content of each case. In addition, the study aimed to establish the features of the comments SBMs mostly focused on in their assessment judgment of PSTs teaching actions and/or abilities. That is, the study focused on the different contexts and variables that mentor teachers commented on.

Contexts are here assumed to reflect the geographical or environmental situations mentors are working in, hence qualitative data was drawn from four provinces of South Africa. These provinces represent particular cultural, historical and geographical contexts; they represent different sampling units of the same sample of TPJs. In each case, we used three TPJs as sampling units, thus forming four categories (4×3 TPJs) of qualitative data collection sources. In other words, their assessment comments may directly or indirectly reflect the contexts and formative interactions that mentors had with the PSTs.

Quantitative data that were used for descriptive purposes within the cases. Twelve journals were used for data collection. Different features or variables within the assessment judgments were quantified by their frequent mentioning in the comments across the four cases and within the journals. In other words, assessment in different contexts is compared across TPJs of the sample or cases.

The quantitative aspect of the study focused on measuring the extent to which the features or elements in the comment appeared and used by mentors. The aspects or features mentioned were measured per TPJ and reflected in the criteria of the lesson plan (Tables 1-4). The criteria are reflected in the sections and subsections of the lesson plan. Each section, subjection or their features are identified by codes and were used in the analysis of the assessment judgment comments.

\section{Results and Analysis}

The results or the analyses are reported according to cases. The cases represent the different contexts. These contexts reflect four geographical South African provinces (Figure 1).

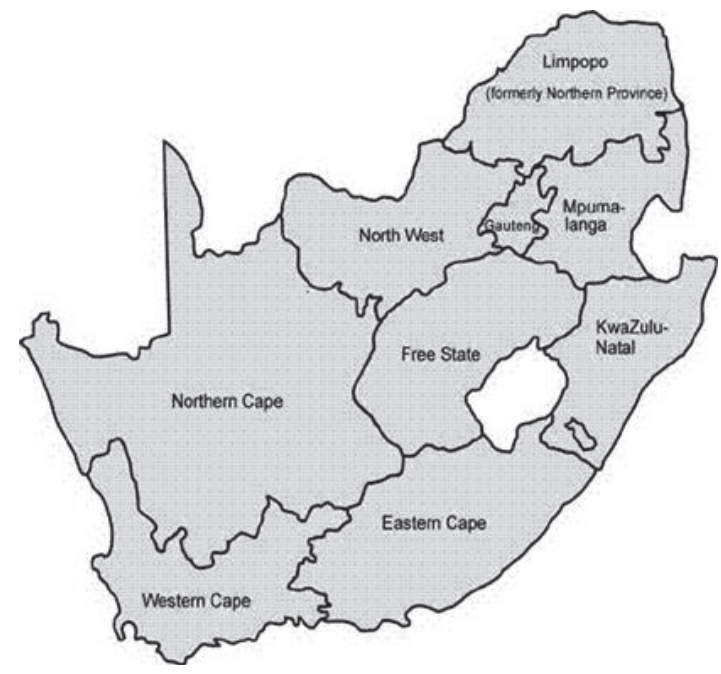

Figure 1: Map of South African provinces

Four provinces, Limpopo (LMP), Mpumalanga (MPL), Gauteng (GTN) and KwaZulu-Natal (KZN), were selected because most of the PSTs in this second-year Bachelor of Education (BEd) programme come from them. Four purposely-selected assessment comments from the TPJs were used for each case.

\subsection{Results of assessment judgment comments}

In this section, we first illustrate the results in the form of assessment comments by individual mentors in different contexts. The comments are reported in three cases of different contexts. Although the reporting is about cases, individual assessments by the mentors have also been analysed for an in-depth understanding of their situations. The unedited comments below are from the four provinces studied: 


\subsubsection{Case LMP}

LMP 001: "The lesson was [introduced in a good format; CR/DA]. He [involved learners and learners ask questions: PP] and the educator was able to [offer feedback: RL]. He [ask what they have learnt: AKK] at the end of the lesson. The voice was loud and clear. Pay attention: [language usage: D\&LU], [class control: CC] teaching must be used at all times" $[\sqrt{ } \sqrt{ } \sqrt{ } \sqrt{ }: 6]$

LMP 002: "The educator is well [grounded in the knowledge and skills: CP] of the subject. The quantity of the voice is good and he is audible. ...Needs to pay attention on [class involvement and discipline: CR/DA]. He [clearly explains the concepts: CP]. [Questions are clear and well answered: PP]....An interesting lesson." $[\sqrt{ } \sqrt{ } \sqrt{ }: 4]$

LMP 003: "She show passion of this job; so far you got what it take to become a good teacher. You know what she is doing and she always dedicates herself in each and every lesson: EM/IL]. The lesson you [know how to present it: CP] and it [being successful to the learners: LOa]. Try your best to [have an atmosphere: CR/DA], a [good atmosphere and be able to ask: AKK] to have [good point on how to motivate: EM/IL] your learners to do your best. Make sure that each and every lesson you [write important thing: LO] and [facts: Lo] to the learners'." $\sqrt{ } \sqrt{ } \sqrt{ } \sqrt{ } \sqrt{ } \sqrt{ }: 8]$

Limpopo is a province in the northernmost part of South Africa from which some of the university's PSTs come.

\subsubsection{Case MPL}

MPL 001: "[Good introduction: CR/DA]. [Logically presented: LP]; [leading questions given: PP]; more needs to be done on [communication: CI]; on [learning material- appropriate but more needs to be done; R] [suitable methods were used; Sm] lesson [outcomes achieved: Lo]. His [lesson planning and presentation: CR/DA] are up to standard. He needs to improve on [time allocation: TM] within the lesson and [learner involvement: CI]." $[\sqrt{ } \sqrt{ } \sqrt{ } \sqrt{ } \sqrt{ } \sqrt{ } \cdot 10]$

MPL 002: "[Lesson was well prepared: LO], [presented] and well done: Lo]. You need to be developed...learn to[discipline learners: CC ]...allow [learners to ask questions: $\mathrm{Cl}$ ] so that your teaching will be effective but everything was well done." $[\sqrt{ } \sqrt{ } \sqrt{ }: 4]$

MPL 003: "There is less [learner involvement: $\mathrm{Cl}$ ] in the class. No [appropriate reinforcement: loKK] was given when a learner answers a question. More problems can be assigned to learners so as to answer the achievement of required [learning outcome: Lo]." $[\sqrt{ } \sqrt{ }: 3]$

Mpumalanga is the province that borders Mozambique in the eastern part of South Africa. This province, unlike the other three provinces in this study, does not have a university where teachers or mentors are trained. Its context is totally different in academic terms as far as mentors' experiences are concerned.

\subsubsection{Case GTN}

GTN 001: "Introduction-this was relevant: CR/DA] to [link learners' pre-knowledge with new concepts: LNK]; [used drawings to illustrate magnetic field; EoC] actualisation of content:] through exercise; learners represented well. Generally she handled [classroom management and control: CC] very well." $[\sqrt{ } \sqrt{ } \sqrt{ }: 4]$

GTN 002: "The educator shows [good content knowledge: LP] e.g. ...the [concepts were dealt with very well: CP). He has a very good quality of voice and he is the [master of the subject: EoC]. The [lesson plan reflected everything that was to be done: LO]." $[\sqrt{ } \sqrt{ } \sqrt{ }: 4]$

GTN 003: "...the student is a hard worker and he is too cooperative and listens to other people's advice. He did [present the lesson according to the way [that learners had understood: Lo] it. [Learners were also active: Ac] when he presents lessons. Learners were [actively involved: Ac] in the lesson throughout the whole period. According to the way he had presented the lesson, I guarantee that even if he can be employed he will do the best and he seems to be a good future educator." $[\sqrt{ } \sqrt{ } \sqrt{ }: 3]$

Gauteng is the province in the middle part of South Africa. It is privileged in terms of resources, especially educational resources. It is also the economic engine of the country.

\subsubsection{Case KZN}

KZN 001: "She needs to [link her lesson] with previous lessons: loKK. [Next lessons need to be indicated: LO] and relevant. The student teacher also needs to bring more [teaching media: Ad] into the classroom in order to enhance teaching and learning." $[\sqrt{ } \sqrt{ } \mathrm{V}: 3]$

KZN 002: "There is a [lack in terms of lesson plan: LO] design. Need to improve on usage of different [teaching method: Ad]. Learners need to [be told what is expected of them: Lo] at the end of the lesson". $[\sqrt{ } \sqrt{ }: 3]$

KZN 003: "She prepared very well for the lessons and give[s] the learners examples: EOC] and she [assist learners: AC] 
that are struggling to follow very fast". $[\sqrt{ } \sqrt{ }: 3]$

KwaZulu-Natal is in the southeastern part of South Africa. Most of the university's PSTs come from the rural parts of this province.

The geographical areas are here meant to reflect different contexts of the mentors' working environments and the influence these areas could have had on their judgment decision-making processes. The short description of each province demonstrates the different contexts in which mentors assessed practicum. Table 1 below illustrates a summary of the analysis of the mentors' assessment judgment comments made about PSTs' teaching and lesson plans in different contexts. The table reflects analysis of combined comments drawn from TPJs per province or context. There are apparent assessment differences across and within cases and individual mentors' comments.

Table 1: A summary of the mentors' teaching and lesson plan assessment

\begin{tabular}{|c|c|c|c|c|}
\hline \multirow{3}{*}{\begin{tabular}{|l|} 
Aspects in the Criteria \\
1. Professional Conduct (PC) \\
Appearance (A); teaching style (TS); delivery and language usage (D\&LU) and \\
class control (CC).
\end{tabular}} & \multicolumn{4}{|c|}{$\begin{array}{c}\text { Frequencies }(\sqrt{ }) \text { of features of criteria, e.g. PC: } \\
\text { (A); (TS) commented on by mentors }\end{array}$} \\
\hline & Case LMP & Case MPL & Case GTN & Case KZN \\
\hline & $2(11 \%)$ & $1(5.9 \%)$ & $0(0 \%)$ & $0(0 \%)$ \\
\hline $\begin{array}{l}\text { 2. Lesson Preparation (LP) } \\
\text { learning outcomes(LO); assessment criteria (AC) and lesson outcomes (Lo) }\end{array}$ & $2(11 \%)$ & $4(23,5 \%)$ & $2(22,2 \%)$ & $4(50 \%)$ \\
\hline \multicolumn{5}{|l|}{ 3. Presentation of the lesson (PoL) } \\
\hline $\begin{array}{l}\text { 3.1 Introduction (INT) } \\
\text { Create relationships/desirable atmosphere (CR/DA); effect motivation and } \\
\text { inclination to learning (EM/IL); pose problems for new knowledge (PP); link new } \\
\text { knowledge to real life situation (LNK). }\end{array}$ & $7(38,9 \%)$ & $3(17,6 \%)$ & $2(22,2 \%)$ & $0(0 \%)$ \\
\hline \multicolumn{5}{|l|}{ 3.2 Exposition and actualisation of the new learning content (EAL) } \\
\hline $\begin{array}{l}\text { Mastery of learning content (MLC) } \\
\text { Logical presentation, clearly presented (CP). }\end{array}$ & $3(16.7 \%)$ & $0(0 \%)$ & $1(11.1 \%)$ & $0(0 \%)$ \\
\hline $\begin{array}{l}\text { Didactic flexibility (DF) } \\
\text { Accommodation of circumstances (Aoc); reaction to learners(RL); continuous } \\
\text { evaluation (CE); }\end{array}$ & $1(5.6 \%)$ & $0(0 \%)$ & $0(0 \%)$ & $1(12.5 \%)$ \\
\hline $\begin{array}{l}\text { Communication and learner involvement(CLI): } \\
\text { class involvements (Cl); individualisation (I); activity (Ac); explanation of } \\
\text { concepts (EoC); }\end{array}$ & $0(0 \%)$ & $4(23.5 \%)$ & $4(44.4 \%)$ & $1(12.5 \%)$ \\
\hline $\begin{array}{l}\text { Actualisation of content }(\mathrm{AoC}) \\
\text { Determine if learners achieved knew knowledge (AKK) }\end{array}$ & $2(11.1 \%)$ & $0(0 \%)$ & $0(0 \%)$ & $0(0 \%)$ \\
\hline $\begin{array}{l}\text { Teaching media (TMed) } \\
\text { suitability (Stm); relevancy }(R) \text {; adequacy }(A d) \text {; originality }(0)\end{array}$ & $0(0 \%)$ & $1(5.9 \%)$ & $0(0 \%)$ & $1(12.5 \%)$ \\
\hline $\begin{array}{l}\text { Methods/techniques (M/T) } \\
\text { suitability }(S m) ; \text { meaningfulness (MfN); effective (E); successful (Scf) }\end{array}$ & $0(0 \%)$ & $1(5.9 \%)$ & $0(0 \%)$ & $0(0 \%)$ \\
\hline $\begin{array}{l}\text { 3.3 Conclusion(CON) } \\
\text { Lesson outcomes achieved (LOa); integration of new knowledge (IoKK); } \\
\text { application (App); synthesis (Syn); evaluation of new knowledge (EoKK);time } \\
\text { management (TM) }\end{array}$ & $1(5.6 \%)$ & $3(17.6 \%)$ & $0(0 \%)$ & $1(12.5 \%)$ \\
\hline Total number of aspects commented on: & 18 & 17 & 9 & 8 \\
\hline
\end{tabular}

The discussions that follow will draw from the results as reflecting the questions that were posed and/or from any aspect that may have emerged in the analysis process.

\section{Discussion of Results}

In their study of work-based learning, Brodie and Irving (2007) suggest a focused assessment. They argue that in order to effectively assess teaching practice or work-based learning, assessment should focus on knowledge demonstrated during the act. In this study, the act was the PSTs' teaching of a lesson, hence the focus of assessment would be on aspects of the lesson as described according to variables in the criteria. In other words, a focused assessment or its feedback of or about the lesson needs to be accurate, appropriate, relevant, and comprehensive (Sadler, 1998), especially for formative purposes. The comments as reflecting feedback need to be on defined aspects of the 
assessment criteria for teaching a lesson. Additionally, all aspects for teaching a lesson must be equitably assessed for every PST of the cohort despite the diversity of contexts. Equity in diversity is the inclusive and comprehensive assessment principle articulated by both the CHAT and the SJT. The discussion of the results is therefore mindful of the two theories within the limitation of the framework of the lesson plan (Table 1). The analysis and the discussion within the lesson plan framework constitute assessment of the lesson plan as a data collection instrument and are meant to highlight its limitations and/or strengths. The discussion is based on the analysed assessment judgment comments (Table 1) from the three cases (contexts) and the individual comments made by SBMs within the three contexts.

\subsection{Professional Conduct (PC)}

At a glance, the focus on this aspect and/or variables within it are given less prominence or importance during assessment by SBMs in the three contexts. This assertion is demonstrated in the limited comments on the different aspects of the criteria. Although in two contexts (i.e. LMP and MPL) some aspects within this variable of the criteria were commented on, the comments were limited to only two variables; delivery and language usage and classroom control. The comments were also of low frequency (i.e. $11 \%$ for LMP and 5.9\% for MPL) in terms of the total comments within these contexts. These are two important variables of the criteria of any school teaching situation and some comment about them is expected from any assessment feedback. In the other two contexts (i.e. GTN and KZN) this aspect of the criteria (PC) was ignored. It can therefore be concluded that there is no equity in what is assessed and/or the extent of assessment. Assessment of professional conduct is therefore varied within and across contexts.

\subsubsection{Lesson Preparation (LP)}

This section of the lesson appears to be the focus of most SBMs. Comments on aspects or variables within this facet were made in all the contexts (KZN with $50 \%$ of its total comments) in this study. However, the frequency of comments varies as there are different emphases. The emphasis under this aspect is on outcomes, with lesson outcomes (Lo) the most emphasised. Assessment criteria (AC) were mentioned in only one context (KZN) and by one assessor. In this context (KZN) all aspects of the lesson were mentioned in the feedback, making assessment of LP relatively the most commented about in all contexts. In the KZN context it was the most comprehensively commented on.

\subsubsection{Presentation of the lesson (PoL)}

Presentation of the lesson is a main section within the lesson plan framework of the instrument. It is therefore the focus area of assessment with subsections. The three subdivisions are: introduction (INT); exposition and actualisation of the new learning content (EAL); and conclusion (CON). We discuss each of them consecutively.

\subsubsection{Introduction (INT)}

Generally, the introduction of a lesson gives first impressions about how one aims to teach or what one's intentions/foci are about the teaching of a particular topic. It is therefore an important area of focus for teaching mentor-assessors. A glance at the assessment on this part of the lesson plan shows varied foci by assessors within and across the four cases or contexts. For example, mentors in LMP (see LMP001; LMP002; LMP003) collectively commented on almost all the aspects of the criteria except for LNK. Conversely, in KZN SBMs did not make any judgment comments concerning variables in the introduction of the lesson by their PSTs. This observation gives a clear picture of how assessment of PSTs doing the same course may differ in their foci of assessment, thus making assessment and feedback less equitable for the same cohort of PSTs within the same programme.

\subsubsection{Exposition and actualisation of the new learning content (EAL)}

This subdivision of the presentation of the lesson plan is itself divided into smaller subdivisions. It is an area where the PST's demonstrates different types of knowledge, skills and values during teaching. The following are some of the areas mentors focused on or were supposed to focus on and/or comment on for feedback purposes: 


\subsubsection{Mastery of learning content (MLC)}

When PSTs undertake the practicum journey, they leave the institution from different areas of specialisation. There are PSTs who specialise in science teaching (e.g. Chemistry, Physics or Biology). It is therefore incumbent upon mentors as assessors that aspects of knowledge in these areas are focused and commented on or about in their assessment, especially for formative feedback purposes. Only mentors from two of the four cases (contexts) (LMP and GTN) made comments about or on aspects of mastery of learning content. Since PSTs or anyone who teaches has to be teaching about something, the teaching of that something needs to be assessed or mentioned in the assessment or feedback. In the case of the practicum, mastery of learning content was ignored in two contexts (MPL and KZN). This omission leads to two conclusions: it may be that the assessors were not specialists in the discipline or their focus was more on other aspects of teaching, such as teaching strategies.

\subsubsection{Didactic flexibility (DF)}

The teacher's flexibility in the classroom illustrates his/her ability to adapt to different classroom contexts, so mentors would recognise it during the PST's presentation of a lesson. In the case of mentors' assessment during this particular practicum and/or lesson there was relatively little commenting in this area. This relatively low percentage (e.g. 5.6\% for LMP; $0.0 \%$ for MPL; $0.0 \%$ for GTN and12.5\% for KZN) within these contexts is demonstrated in the frequencies in the cases. Comments were made in only two contexts (LMP and GTN). Generally, mentors seemed to place little importance on didactic flexibility. Variables within this aspect of the criteria show that PSTs should have demonstrated their interaction skills with learners. Does the lack of comments reflect on PSTs lack of interaction with learners or on SBMs' lack of interest or knowledge about what to assess during these interactions?

\subsubsection{Communication and learner involvement (CLI)}

This aspect has two important components that teachers (or PSTs) need to demonstrate in a classroom, particularly in a science classroom. Communication happens when the teacher engages his/her learners during a lesson when s/he communicates information, when learners ask questions and when s/he asks questions. Mentors should encourage their mentees/PSTs to engage in these interactions. In their assessment of these aspects, mentors in different contextual situations demonstrated different areas of focus. For example, mentors in MPL collectively commented more about the class involvement. In GTN the comments were spread among SBMs on aspects of CLI. In addition, in LMP no mentor mentioned anything on CLI, whereas in KZN a comment about the explanation of content (EoC) was made. From this observation it is clear that contexts play an important role in what should or could be part of feedback and how it should or could be communicated in any assessment situation.

\subsubsection{Actualisation of content (AoC)}

Teaching is an attempt to enhance learners' knowledge about the topic being taught. It is important that the teacher should periodically establish whether learning has indeed taken place. Mentors are therefore obliged to establish whether PSTs assess that learning has taken place in their own teaching. From our summary of data from the four contexts, only mentors from LMP said something about this important reflective exercise. That is, most of the mentors during this period of practicum chose not to comment or give feedback on this aspect. This is another confirmation that contexts play a significant role in what assessors do or say during assessment in general and in particular situations. Furthermore, content is given less prominence in assessment by SBMs. This confirms our observation earlier on assessment feedback on subject matter knowledge. Does this reflect SBMs' interest or lack thereof in the content that is taught? Is it about interest in or knowledge of subject matter? Is it about topic/disciplinary incompetence on the part of assessors?

\subsubsection{Teaching media (TMed)}

There is a general lack of comment on teaching media. It is difficult to interpret what the cause of this may be. It could be that PSTs may not have used any media in their teaching at the university. It could also be that it is impossible to use any media, especially in areas where there are no resources (e.g. electricity) or resources to develop models, for instance in rural areas. Another reason could be that PSTs may not have been exposed or trained in modelling or the use of models in their teaching. Mentors may also not encourage the use of media because of their own training on modelling. The use 
of media or lack thereof is generally low among PSTs in all contexts. As Roth and Lee (2007) indicate, social and material environments influence what we can or decide to do. Our cultural and historical backgrounds to some extent affect our thought processes, including those in education assessment.

\subsubsection{Methods and techniques (M/T)}

Methods and techniques occupy a very important and critical part of teachers' teaching skill. However, comments in all cases or contexts indicate a lack of interest by mentors in this aspect of the criteria. Could this be limitation in mentors' assessment knowledge or skill on this aspect of the criteria? This attitude from mentors in their assessment could be attributed to many other factors. Mentors bring different beliefs into the mentoring process, which may subsequently lead to biased assessment judgments (Hawkey, 1997).

\subsubsection{Conclusion of a lesson}

In this study, we aimed to determine the extent to which mentors (SBMs) engage with their mentees especially to enhance PSTs' knowledge, skills and attitudes about teaching. Therefore, mentors should have commented about the purpose and outcomes of PSTs' lessons, and, in particular, about whether lesson outcomes were achieved and/or their PSTs' ability in establishing whether their learners gained any knowledge during the lesson. Clearly, the extent of the comments and the types of comments varied. This is a reflection of the contexts of assessments and the obvious influence by mentors on the eventual outcome of assessment or feedback on assessment. Maynard and Furlong (1993) argue that teaching and learning environments influence mentors' conceptualisation of teaching and consequently their views of the processes of learning to teach. So how PSTs conclude their teaching will be viewed differently by different assessors, especially in different contexts, as was the case with SBMs in this study.

\section{Conclusion}

Black and William (1998) describe formative assessment as a form of assessment suited to and effective in all educational settings. Our exploration of assessment in different practicum contexts as indicated in the research questions was predicated on Black and William's assertion. In concluding this study, we reflect our findings on mentors' assessment judgments directly from the research questions. Assessment judgment comments as feedback in our study are the SBMs' written "representation of an assessed person's knowledge, skill or understanding" of teaching of a lesson (Newton, 2007, p.158). These judgments are also an attempt to reflect on the mentoring and assessment system used by mentors in assessing the PSTs' lessons. The findings from the following research questions reflect the feedback in mentors' comments.

\subsection{What is the nature and content of mentors' assessment judgment comments on PSTs' teaching capabilities?}

In our introduction of this question, nature and content were defined as a measure of describing the characteristics of the judgment comments in relation to the contents of the criteria. That is, judgments on the PSTs' teaching knowledge, skills and values needed to reflect what is contained in the criteria. In addition, this measure is benchmarked on a certain standard. Since the comments were regarded as representing feedback, the characteristic of formative feedback is also a point of reference in terms of what and how feedback should be given in a given context. According to Sadler (1998), feedback needs to be appropriate, accurate, comprehensive and accessible to the assessed. In addition, Gibbs and Simpson (2004) argue that assessment feedback needs to describe the link to the purpose of the task of teaching and what exactly they have to do.

In our analysis of SBMs' comments in different contexts, we can conclude that mentors differed in terms of the content and the manner it was presented in their judgment comments about their mentees (PSTs). These differences in the nature and content of assessment judgment comments occurred across and within contexts. Differences within comments refer to differences among SBMs in the same context. It can therefore be concluded that diverse contexts geographical, environmental, historical, cultural, economical, academic and experiential - play a significant role in assessors' thought processes and the judgments they make. 


\subsection{What features did SBMs mostly focus on in their assessment judgment comments of PSTs teaching actions and/or abilities?}

In counting aspects/variables within the assessment instrument that SBMs' referred to in the judgment comments, lesson plan (LP) and introduction (INT) of the lesson appear the most frequently mentioned. However, this frequency differs from context to context and from assessor to assessor. The variable least referred to is teaching media. The low frequency of reference to this aspect is consistent across and within cases or contexts. Our conclusion is that there is little use of teaching media by PSTs in their lessons during practicum. This could also be a reflection of SBMs' focus on the PSTs' use of teaching media arising from their training or experience in using teaching media in their own teaching.

\subsection{What is the quality of SBMs' assessment judgment comments of the lesson teaching capabilities of PSTs?}

Quality is a concept generally used to measure how something is or how well it is done. In this study quality as a concept was used to describe how well feedback was given and how appropriate, relevant and accurate it was in reference to the criteria of the instrument of measurement. In addition, the study was an evaluation of the assessment instrument (teaching practice journal). The analysis of SBMs' assessment judgment comments revealed a generally poor quality of feedback. That is, most judgment comments were not comprehensive; they were limited in addressing all aspects in the criteria of the assessment instrument. Limited comments reduce accuracy as only some aspects of the criteria are addressed. In some instances, inappropriate comments led to deviations from the set criteria. Assessment must be within criteria and be specific to the actions/performance of the PST in the teaching process. For example, the comment by GTN 003: "...according to the way he had presented the lesson, I guarantee that even if he can be employed he will do the best and he seems to be a good future educator" needs to be clarified as to how the PST presented the lesson in order to provide him/her with opportunities for closing the gap in performance between current and desired performance (Nicol \& MacFarlane-Dick, 2006). This type of comment is not accessible (Sadler, 1998) to the PST for formative purposes or future use to enhance his/her knowledge and skills in teaching. Furthermore, this comment is not catered for in the instrument but may be used for motivational purposes as suggested by Gold (1996), who argues for instructional support that enhances knowledge and skills development and for psychological support that builds confidence and encourages self-esteem.

In concluding this study, we highlight the importance of quality assessment and quality in assessment and the limitations the assessment instrument imposed on SBMs ability to assess. The instrument did not provide sufficient space to comment comprehensively on all aspects of the criteria. Even if PSTs are assessed in different contexts by different SBMs the instrument design must be such that it limits deviations from what should and can be assessed. It is also vital that processes of assessing this important element of teacher preparation are consistent and equitable. Consistent and equitable elicitation of assessment information, especially for formative purposes, ensures that teacher preparation programmes, particularly in diverse contexts, produce the same quality of teachers irrespective of where practicum is conducted.

\section{References}

Beijaard, D., \& Verloop, N. (1996). Assessing teachers' practical knowledge. Studies in Educational Evaluation, 22(3), $275-286$.

Black, P., \& William, D. (1998). Inside the black box. London: Kings College.

Brodie, P., \& Irving, K. (2007). Assessment in work-based learning: Investigating a pedagogical approach that enhances student learning. Assessment and Evaluation in Higher Education, 32(1), 11-19.

Crasborn, F., Hennissen, P., Brouwer, N., Korthagen, F., \& Bergen, T. (2008). Promoting versatility in mentor teachers' use of supervisory skills. Teaching and Teacher Education 24(3), 499-514.

Crossouard, B. (2009). A sociocultural reflection on formative assessment and collaborative challenges in the states of Jersey. Research Papers in Education, 24(1), 77-93.

Dall'Alba, G., \& Sandberg, J. (2006). Unveiling professional development: A critical review of stage models. Review of Educational Research, 76(3), 383-412.

Darling-Hammond, L., Bransford, J., LePage, P., Hammerness, K., \& Duffy, H. (2005). Preparing teachers for a changing world: What teachers should learn and be able to do. San Francisco, CA: Jossey-Bass.

Engeström, Y. (1987). Learning by expanding: An activity-theoretical approach to developmental research. Helsinki: Orienta-Konsultit Oy.

Gibbs, G., \& Simpson, C. (2004) Conditions under which assessment supports students' learning. Learning and Teaching in Higher Education, 1(1), 3-31.

Gold, Y. (1996). Beginning teacher support: Attrition, mentoring, and induction. In J. Sikula (Ed.), 
Handbook of research on teacher education, 548-594. New York: Macmillan.

Haigh, M., Ell, F., \& Mackisack, V. (2013). Judging teacher candidates' readiness to teach. Teaching and Teacher Education, 34(August), 1-11.

Hawkey, K. (1997). Roles, responsibilities, and relationships in mentoring: A literature review and agenda for research. Journal of Teacher Education, 48(5), 325-335.

Hodgson, C. P. (1976). The Assessment of teaching practice: What criteria should we choose? Australian Journal of Teacher Education, 1(2). [online] Available at: http://dx.doi.org/10.14221/ajte.1976v1n2.1. Accessed on 31/07/2014.

Hudson, P., Spooner-Lane, R., \& Murray, M. (2013). Mentoring explicit: articulating pedagogical knowledge practices. School Leadership \& Management: Formerly School Organisation, 33(3), 284-301, DOI: 10.1080/13632434.2012.724673

Leshem, S. (2012). The many faces of mentor-mentee relationships in a pre-service teacher education programme. Creative Education, 3(4), 413-421.

Maynard, T., \& Furlong, J. (1993). Learning to teach and models of mentoring. In D. Mclntrye, H. Hagger, \& M. Wilkin (Eds.), Mentoring: Perspectives on school-based teacher education, 69-85. London: Kogan Page.

McDougall, L. Mtika, P., Reid., I., \& Weir, D. (2013). Enhancing feedback in student-teacher field experience in Scotland: The role of school-university partnership. Professional Development in Education 39(3), 420-437.

Morris, S (1970). The assessment and evaluation of teaching practice. In Towards evaluation: Some thoughts on tests and teacher education. Educational Review, occasional publication, University of Birmingham, School of Education, 4, 64-70.

Newton, P.E. (2007). Clarifying the purposes of educational assessment. Assessment in Education: Principles, Policy \& Practice, 14(2), 149-170.

Nicol, D.J., \& Macfarlane-Dick, D. (2006) Formative assessment and self-regulated learning: A model and seven principles of good feedback practice. Studies in Higher Education, 31(2), 199-218.

Sadler, D.R. (1998). Formative assessment: Revisiting the territory. Assessment in Education, 5(1), 77-85.

Roth, W., \& Lee, Y. (2007). Vygotsky's neglected legacy: Cultural-Historical Activity Theory. Review of Educational Research, 77(2), $186-232$.

Smith, K. (2010). Assessing the practicum in teacher education: Do we want candidates and mentors to agree? Studies in Educational Evaluation, 36, 36-41.

Taras, M. (2002). Using assessment for learning and learning from assessment. Assessment and Evaluation in Higher Education, 26(6), 501-510.

Tillema, H.H. (2009). Assessment for learning to teach: Appraisal of practice teaching lessons by mentors, supervisors and student teachers. Journal of Teacher Education, 60(2), 155-167.

Wang, J. (2001). Contexts of mentoring and opportunities for learning to teach: A comparative study of mentoring practice. Teaching and Teacher Education, 22(1), 22-31. 